characterised by Rapidity of Growth and Abnormal Weight." The paper was illustrated by naked-eye and microscopic specimens (see p. 112).

Dr. LEEPER remarked that the case presented by Dr. O'Neill was of great interest to him. In these cases the production of melanin in such an enormous quantity in the body in such a short period was very astonishing. He understood that melanin was produced by the action of an enzyme upon a proteid. In a case somewhat similar to the case of Dr. O'Neill which he had treated in St. Patrick's Hospital, the first noticeable symptom was a small black nodule the size of a pea on the skin of the patient's forearm. Within one fortnight this patient's whole body was covered with multiple round-celled melanotic sarcomata, and at the autopsy granules and round pea-like tumours were found in the cerebral cortex and cere. bellum. The primary growth seemed to have been in the great omentum. Dr. Leeper wondered why these melanotic sarcomata did not appear to spring from those seats in the body where melanin was a normal constituent, like the locus niger and elsewhere. In his case, although melanotic sarcomata were freely scattered through the frontal and parietal lobes and the cerebellum, no increase of melanin was observed in the locus niger or locus caruleus, which seemed to point to the fact that the melanin found in the sarcomata was a different substance chemically from the normal melanin of the body.

The SRCRETARY said that the microscopic preparations seemed to bear out Mr. Handley's view that the propagation of sarcoma took place by continuous growth of the cells along the lymphatics, as lymphatics containing pigmented sarcoma-cells were to be seen in many places in the specimens shown.

Dr. O'NriLl, in replying, stated he had shown the liver to an Army surgeon of nearly twenty years' experience in India, where diseases of the liver are so prevalent, and said he had never come across such a remarkable case. It was a cause of great regret that there had been no examination of the brain, but, as he had already stated, this was not possible. Coley (1) refers to a case where a small tumour was found in the palm of the hand, and although removal was urgently suggested the patient refused. Later on she placed herself in the hands of Christian Scientists, who persuaded her that she was getting better, but ultimately the arm had to be amputated. Coley has also recommended treatment of inoperable sarcoma with mixed toxins of erysiples and Bacillus prodigiosus. The liver appears to be the largest ever recorded.

The meeting terminated.

\title{
NOTE ON THE USE OF PADDED ROOMS AND THE PRACTICE OF LOCKING UP PATIENTS BY DAY IN SINGLE ROOMS.
}

By Grorge M. Robrrtson, M.B., F.R.C.P.Edin., Physician-Superintendent, Royal Edinburgh Asylum, Morningside.

In the October number of the Journal I have been taken to task (p. 750) for having " been indiscreet in classing as undesirable some practices which have been shown to be uncontrovertibly sound on grounds of reason, as well as of emotion, and only to be inapplicable when wrongly applied." These practices are the use of padded rooms and what is technically called "seclusion," but which is simply and accurately described as locking up patients by day in single rooms. I must again say that I do consider these practices undesirable, that I do not admit them to be urcontrovertibly sourd, and that the propriety of their application at all times is open to doubt. As I have had an experience of twenty-one years' duration full of experimental research into methods, and as the opinions expressed above have been founded on this personal experience, I feel myself on fairly solid ground.

In the first place I consider the two practices as essentially undesirable as they can possibly be, and I place them, though on a lower level, in the same category as mechanical restraint, which is only resorted to most exceptionally and in the direst necessity. Of course, it is possible to say that if mechanical restraint be necessary and does good in one case for one day in 100,000 , that to that extent the practice of it is desirable. A similar limited desirability may be claimed for the padded

LVII.

(1) Phil. Medical Fournal, 190t. 
room and the single room. When flogging was in vogue the same was no doubt claimed for it with similar reason. A patient was pointed out to me in an asylum who was troublesome and would not employ himself, till one day he was soundly thrashed by another patient for these faults and he became a reformed and useful person ever after. I have, therefore, no doubt that could the madhouse keepers of the past come to life, they could easily demonstrate to us that flogging was desirable because it did good, and that it was only inapplicable when wrongly applied. Would any of us now adopt the practice?

The broad way of looking at this question, taking everything into consideration, cannot fail to convince one that the practice of locking up sick persons under medical care for treatment, in padded rooms and single rooms is undesirable. It is a form of "treatment" which has been handed down to us from the past, and it had its origin in, and was adopted from, the jails. It became naturalised in the madhouses of one hundred years ago because thesejinstitutions were not mental hospitals, but prisons for the insane. I venture to say that no medical student from the hospitals or young graduate, seeing the practice adopted for the first time, but feels more keenly its prison-like characteristics with compassion for the individual sub. jected to it, than a realisation of its medical and therapeutic blessings. Familiarity of experience, of course, blunts these feelings, and the conservatism of human nature may in the end commend the practice to many, but the sight of a patient locked up in a room will never fail to create an impression, often indelible, on a layman visiting an asylum for the first time. This impression is never favourable, and it is always accompanied by sympathy for the unfortunate sufferer.

Another circumstance in connection with these practices is that the general public have an idea that a large number, if not the majority, of our patients are treated in this manner. So much depends on our good name that the existence of this misconception and its removal is a most important matter to all who have the welfare of the insane at heart. I have taken hundreds of students and numberless deputations of public bodies round asylums, and they have all shown an exaggerated and even morbid interest in the padded room. It is hardly too much to say that in the eyes of the public it is the feature of asylum treatment which is characteristic of the institution, and it is magnified in importance and in frequency of employment out of all semblance to the truth. I had a personal experience of this fact lately at a dinner given by a club in honour of a retiring Commissioner in Lunacy. The menu was illustrated with his portrait in the guise of a knight in armour, and on his shield was the device of a female standing in a padded roomto my mind a most unhappy and inappropriate choice of subject, but it illustrates how the public think.

Then, if we take the feelings of the patients on the practice, we find that it is not popular with those who can express themselves. There are rare exceptions, but the vast majority object to it as insulting and offensive to them. One patient, who came to me from another asylum, where she was periodically locked up by day in a single room, wrote home to her friends that the place she had now come to was not an asylum at all, as no one had dared to lock her up. She was quite easily managed without doing so. The patients' friends are not, it is true, usually told about these occurrences, but when they do hear they do not think the practice desirable. A few months ago the mother of a transferred patient called at my house to thank me on behalf of herself and her daughter for not putting her daughter in the padded room for recurrent excitement.

I have, further, to refer to one more point: the effect the knowledge has on the nursing staff that locking up patients in rooms is regarded by the medical officers as a legitimate, recognised, and regular form of treatment in suitable cases. I observed in an asylum where the practice was used that the nursing staff was very ready to suggest, directly or more usually indirectly, resort to this method of treatment in all troublesome cases, and, moreover, that failure to acquiesce in these suggestions, and to order it, on the part of the medical officers, was more or less openly resented. On the other hand, in an asylum where confinement by day in a single room or padded room had never been used, and this form of treatment was not recognised, it was never hinted at or thought of by the staff, and there was no unpleasantness of feeling generated if it was not ordered. I have also found that in those asylums where it was not resorted to, the nursing staff were more patient with troublesome patients and were more full of resources in devising other 
means of coping with the difficulties that arose. I therefore have no hesitation in saying that the practice has a demoralising effect on the staff to this extent, and it is only what anyone with a knowledge of human nature would naturally expect.

I think everyone will agree that this form of treatment is one which may be abused, even when the greatest care be taken, and this is an additional strong reason for having as little to do with it as possible, as we are all human and liable to err. I will give one of my own experiences in an asylum where locking up in single rooms was practised, but was kept, as I then thought, within reasonable limits. On one occasion I ordered an adolescent girl to be placed in the padded room. For several days afterwards when I visited her I received tales of her excitement and violence, and the number of nurses it took to control her when she was fed, washed, etc., so that any suggestion of mine for her removal from the padded room was instantly set aside as a demonstrated impossibility. One of the nurses, however, came to me privately, and under promise of secrecy told me I was being systematically deceived by exaggerated reports, and that there was nothing to prevent the girl leaving the padded room. This was a lesson on the weakness of human nature where selfish interests are involved that $I$ have never forgotten. So fully realised, however, is the danger of abusing this form of treatment that the authorities most properly compel us to keep a written record of it in our registers, and it is also a significant and instructive fact that since the Board of Lunacy for Scotland started to ask for quarterly returns of this, and to publish them, the total amount of locking up by day has decreased in the most markes manner. I therefore feel justified in believing that so surely as the time had already come when all mechanical restraints have been discarded, save in exceptional cases of direst necessity, so will the day come when this unmedical tradition will also be given up and be employed only in the most exceptional circumstances.

If all these facts be taken into consideration and be judicially weighed in the balance, one can scarcely fail to come to the conclusion that the practice has very serious objections, and is, therefore, undesirable.

In the second place, is the practice "uncontrovertibly sound"? To be so, it appears to me that two conditions would require to be fulfilled. The practice would require to be, in the first place, of as great, if not greater, benefit to the patient than any other treatment directed to the same ends. In the second place, the disadvantages associated with the practice would require to be as few, if not fewer, than those associated with alternative forms of treatment. Now, for purposes of argument, let us here admit that as regards the symptoms to be treated the practice of confinement to padded and single rooms is as good as any other. The drawbacks, however, of which I have mentioned some, are of so serious a nature, and so opposed to the fundamental ideals of medical and of hospital treatment, that almost any alternative as good, or even nearly as good, would be preferable. It has to be remembered, in this respect, that the resources of asylum treatment have enormously increased of recent years. The numerical strength of the staff of the asylum of the present day is probably three times that of the asylums at the beginning of the last century, and the increase of skill, intelligence, devotion to duty, and discipline are even more striking than the increase in numbers. Our resources in the way of drugs and the methods of administering them; including hypodermic medication, are infinitely superior to those of the past, and the watchful care with which the development of acute symptoms is followed by the medical officers and the heads of the nursing staff makes the asylum of the present day a totally different place for treatment from the prison-like madhouse of the past, where the practice of locking up patients was originally introduced.

Let us, however, consider the uses of padded rooms, to which my attention is directed, and consider if the alternative methods of treatment that now exist be not quite as good, if not better. In the first place, their usefulness in cases of delirious insanity is pointed out. These cases, in my opinion, should be treated just as cases suffering from the analogous delirium of pneumonia or typhoid fever are treated, vis., by appointing special nurses and attendants to sit beside their beds and give them the continuous supervision, attention and nursing they undoubtedly require. I have never allowed such cases to be locked up in padded rooms, as I consider that all the resources of nursing are required for their proper treatment and recovery. In the second place, it is pointed out that the padded room is a safe and a soft place for weak and feeble patients to tumble about in. Again, I say that 
such patients, usually aged and infirm, require personal care and supervision, and should get it. To lock such patients up in padded rooms is, in my opinion, a cheap but an objectionable way of preventing them from hurting themselves, and although I know it has been recommended in the past, I have never adopted it. It is neither medical treatment, personal care, nor modern nursing ; it appears to me to be rather the negation of all active supervision and attention. The value of "seclusion" was also pointed out to me, but everyone knows by this time who has read my article in the last number of the Journal on the "Treatment of Mental Excitement," that I recognise its value most thoroughly and practice it constantly and largely. This, however, is never done by locking up patients, as I consider this an objectionable and harmful addition to a most useful mode of treatment, and I have found it to be quite unnecessary when special nurses and attendants were provided.

Finally, it is stated that these methods are only "inapplicable when wrongly applied." Now this is a truism that may mean anything in practice, depending, as it does, on one's opinions. Theoretically, I can conceive of the necessity of locking a patient in a padded room as the best, and even the only means of treatment, but practically, I have admitted 3,000 cases and have waited over fifteen years without getting a suitable case to which to apply it. When the price of rubber was high during the rubber boom I was sorely tempted to strip the pads off the rooms and sell them for what they would bring. I still have padded rooms and an open mind on the subject of their use, and when I meet a case to which their employment is applicable, then I will apply it. This exceptional case will make no difference to my views, or to my practice, or to my argument. I have stated that the padded room has "become practically unnecessary," and in spite of the above admission I think the statement is perfectly justified. There has never been one at the Perth District Asylum, nor in the Glasgow District Asylum at Woodilee, and no doubt very many other institutions besides. An American superintendent recently came round this place who had never seen one in his life.

In having been able to carry out the purely medical lines of treatment indicated above by means of the adoption of continuous personal supervision by special nurses, as opposed to the older practice of locking up patients in padded and single rooms, I was indebted in the past to the enlightened and generous view the Stirling District Lunacy Board took of their responsibilities to their patients by supplying a staff adequate for these purposes. The great resources at the disposal of the Royal Edinburgh Asylum of course enable its Board to carry out any policy that has the sanction of modern science. In the end it largely comes to this, that the practice of locking up patients in padded rooms and single rooms has the recommendation of economy, because special attendants and nurses are not then required to look after the patients-an admission frankly made to me the other day by a physician who employed these practices. It was largely for this reason that patients used to be kept under restraint in the old asylums, there not being a sufficiently large staff to look after them in any other way. But just as mechanical restraint has been given up and personal supervision has taken its place, though more expensive, so I am convinced the practice of locking up a patient to enable him to tumble about safely in padded rooms, or to get the advantages of seclusion, will also soon be a thing of the past. The modern ideal at all events is worth striving for.

\section{Note BY THE ReVIEWER.}

Dr. Robertson has not added much of value by way of explaining or supporting those points in his report to which was taken, and is still taken, strong objection. He continues to advocate advances in treatment rightly enough, and he adds some not very uncommon experiences which have come to him in his twenty-one years of practice. The recital of his beliefs would have been more acceptable had the fact that they are entirely shared by his colleagues been made more prominent. On the other hand, when one reads a wholesale denunciation of discarded practices, accompanied by a full explanation that they are not used by the denunciator, it is not unpardonable to fear that the casual reader would conclude that some of us are farther from salvation than that denunciator.

Dr. Robertson has missed the chief point which prompted the terms of the review. In his report he describes the disuse of the padded room and seclusion as 
an "instance of characteristic asylum practices which have been discarded." They have not, as a matter. of fact, been discarded. Dr. Robertson himself last year secluded a patient on account of "maniacal and dangerous excitement," no doubt on uncontrovertibly sound grounds. If the public are so prone to act on the principle of ex uno disce omnes, as he proceeds to show with some particularity, we should fear for the reputation of Morningside on account of the grave departure from principle involved in the use of a discarded practice. We have little doubt that Dr. Robertson would triumphantly emerge from the difficulty created by himself, but will it be so easy for others, who may, perhaps, have but little confidence and much desire to abstain from baring their souls to the public gaze, to explain away their occasional use of a vigorously proscribed practice? That is one of the chief points which troubled the mind of your reviewer.

A feeling of some reverent thankfulness to those who have gone before and made the path so easy for the re-discovery of much that they found out, makes it aggravating to see harsh terms applied to their splendid work and adventuresomeness. Kicking down the ladder on which we have climbed to a height, and are still climbing higher, is ungracious, not to say questionable.

And now I may point to the revised view taken by Dr. Robertson in his letter. There he speaks of the practices as discarded, "except in occasional cases of the direst necessity." Cadit quastio !

Concerning the effect of these practices on the morale of the staff, my statement purposely included a "strong" prescriber. If a superintendent who has to use them permits, or is affected by, his staff resenting his discretion in use, then the conditions of my statement are hardly fulfilled.

Finally, Dr. Robertson is wrong in assuming that the frail patients, for whom I claim the benefits of the padded room, are necessarily locked up in them or withdrawn from skilled and kindly supervision. If his belief runs that way, he has need of yet futher experience before he lays down the law of the padded room.

YOUR REVIEwER.

\section{MEMORIAL TO DR. CONOLLY NORMAN.} UNVEILED BY THE LORD LIEUTENANT.

A memorial to the late Conolly Norman, M.D., F.R.C.P.I., erected in the north choir aisle of St. Patrick's Cathedral, was unveiled by the Lord Lieutenant in the presence of a fairly large congregation on October 18 th, 1910.

The choir and clergy met His Excellency, who was accompanied by the Countess of Aberdeen, at the south-west door of the Cathedral, and moved in procession to the north choir aisle. Then the Succentor read the appointed prayers and collects, after which the hymn, "Nearer my God to Thee," was sung.

\section{Address by Lord Lieutenant.}

The Lord Lieutenant said, "We have assembled here to dedicate a memorial to one whose character and work rendered him worthy, indeed, of such a tribute. Most appropriate, too, is it that this commemorative effigy should be erected within this building, which is pervaded by so many hallowed memories and associations. For our friend, though called hence comparatively early in life, had truly 'served his day and generation before he fell on sleep'; and not only so, but his service was of that high rank which attaches to all true effort for the alleviation of the ills of humanity, and surely never more so than in the case of that mysterious affliction whereby, in a manner often inscrutable, the gifts of reason and intellect are withdrawn. Of Dr. Conolly Norman it may emphatically be said that his heart was in his work. Well do I recollect the occasion when, twenty-four years ago, I first saw him. He was a candidate for the important post which he afterwards occupied for the remainder of his life. At that time the appointment rested with the Lord Lieutenant. I had already formed the definite opinion that he was the right man for the post, but I felt it necessary to abstain from making him aware of this until I had privately informed another candidate, who I knew would be deeply disappointed. On observing my reticence Dr. Norman could not conceal his chagrin. But this only confirmed my opinion regarding him. For it was evident that his eagerness was not caused by mere ambition in a worldly sense, but by the intense 